Goldschmidt 2021 Abstract

https://doi.org/10.7185/gold2021.6152

\section{Characterizing source of arsenic in the sediments of Pozzuoli Bay (south Italy) using compositional data analysis (CoDA)}

\author{
MR. POORIA EBRAHIMI ${ }^{1}$, RENATO SOMMA ${ }^{2}$, CLAUDIA \\ TROISE $^{2}$, GIUSEPPE DE NATALE ${ }^{2}$, ANNALISE \\ GUARINO $^{1}$, DOMENICO CICCHELLA ${ }^{3}$ AND STEFANO \\ ALBANESE $^{1}$ \\ ${ }^{1}$ University of Naples Federico II \\ ${ }^{2}$ Istituto Nazionale di Geofisica e Vulcanologia (INGV) \\ ${ }^{3}$ University of Sannio \\ Presenting Author: pooria.ebrahimi@unina.it
}

Pozzuoli Bay is a part of Campi Flegrei caldera (Fig. 1), an active volcano with intensive hydrothermal activity. Due to coexistence of natural processes and anthropogenic activities across the area, a debate about source of some elements has been ongoing. We applied compositional data analysis (CoDA) to uncover the statistically meaningful relationships and discriminate between pollution sources in sea sediments. Specifically, sediments were collected from 0-50 cm depth range in the proximal zone $(\mathrm{PZN})$ and $0-20 \mathrm{~cm}$ depth interval in the distal zone (DZN) of shoreline, in a sector of the bay where a steelwork has been active until 90's. The samples were analyzed for major and trace elements, grain size and organic matter (OM) content.

A robust principal component analysis (PCA) was separately applied to PZN and DZN datasets. OM and the shortest distance of sample locations to fumaroles (SDF), coastline (SDC) and seepages (SDS) were considered as external variables. For both zones, the first two principal components (PC1 and PC2) retained $>89 \%$ of the total variance. The following associations were found in PZN: (1) $\mathrm{Hg}, \mathrm{Cd}, \mathrm{Cu}, \mathrm{Pb}, \mathrm{Zn}, \mathrm{OM}$, mud, SDC and SDS; and (2) Al, As, V, Fe, Cr, Ni, sand and SDF. Nevertheless, the associations in DZN were: (1) $\mathrm{Hg}, \mathrm{Cu}, \mathrm{Zn}, \mathrm{Pb}, \mathrm{OM}$, mud, SDS, SDF and SDC; and (2) Al, As, V, Fe, Ni, Cr and sand.

The first associations probably reveal impact of the local industry in PZN and DZN. The positive correlations of the variables with SDC and SDS in PZN likely explain wave turbulence at coast, higher mud and OM levels offshore and insignificant influence of seepages. However, the second associations can be related to the pyroclastic materials of Campi Flegrei. In PZN, As is uncorrelated with SDF and negatively correlated with SDC and SDS which likely show that surface discharge of mixed thermal fluids and municipal wastewaters is a key factor for transporting As to the bay. The PC1 score map (Fig. 1) represents an overview of sediment geochemistry in the study area. The results indicate that CoDA is a powerful tool for detecting pollution source in sea sediments.

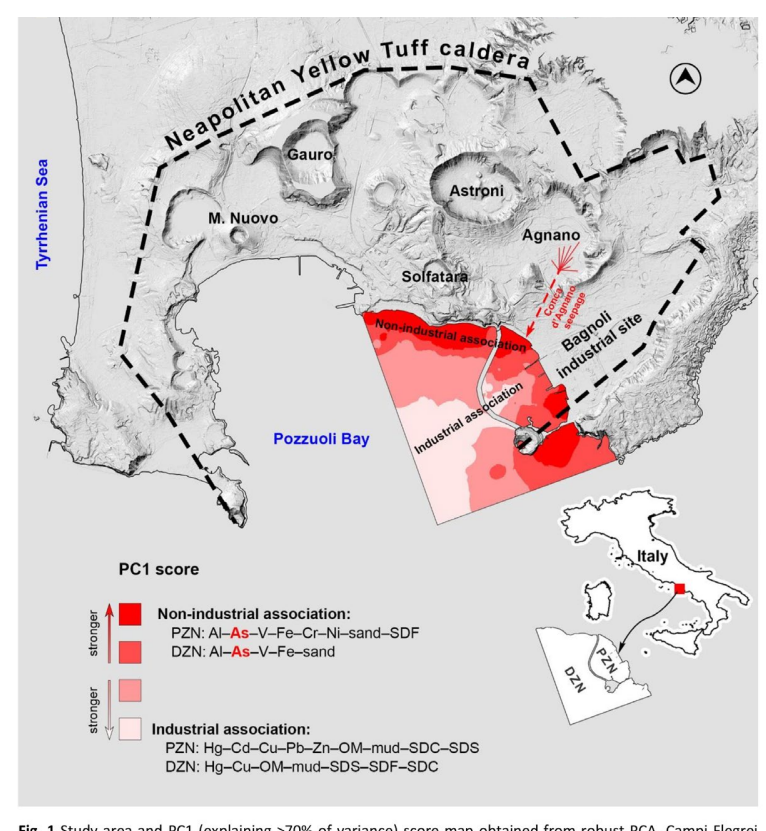
Fig. 1 Study area and PC1 (explaining $770 \%$ of variance) score map obtained from robust PCA. Campi Flegrei
caldera formed by an ignimbrite eruption (i.e. Neapolitan Yellow Tuff) $15 \mathrm{ka} \mathrm{BP.}$ 